\title{
BLICKDIAGNOSE
}

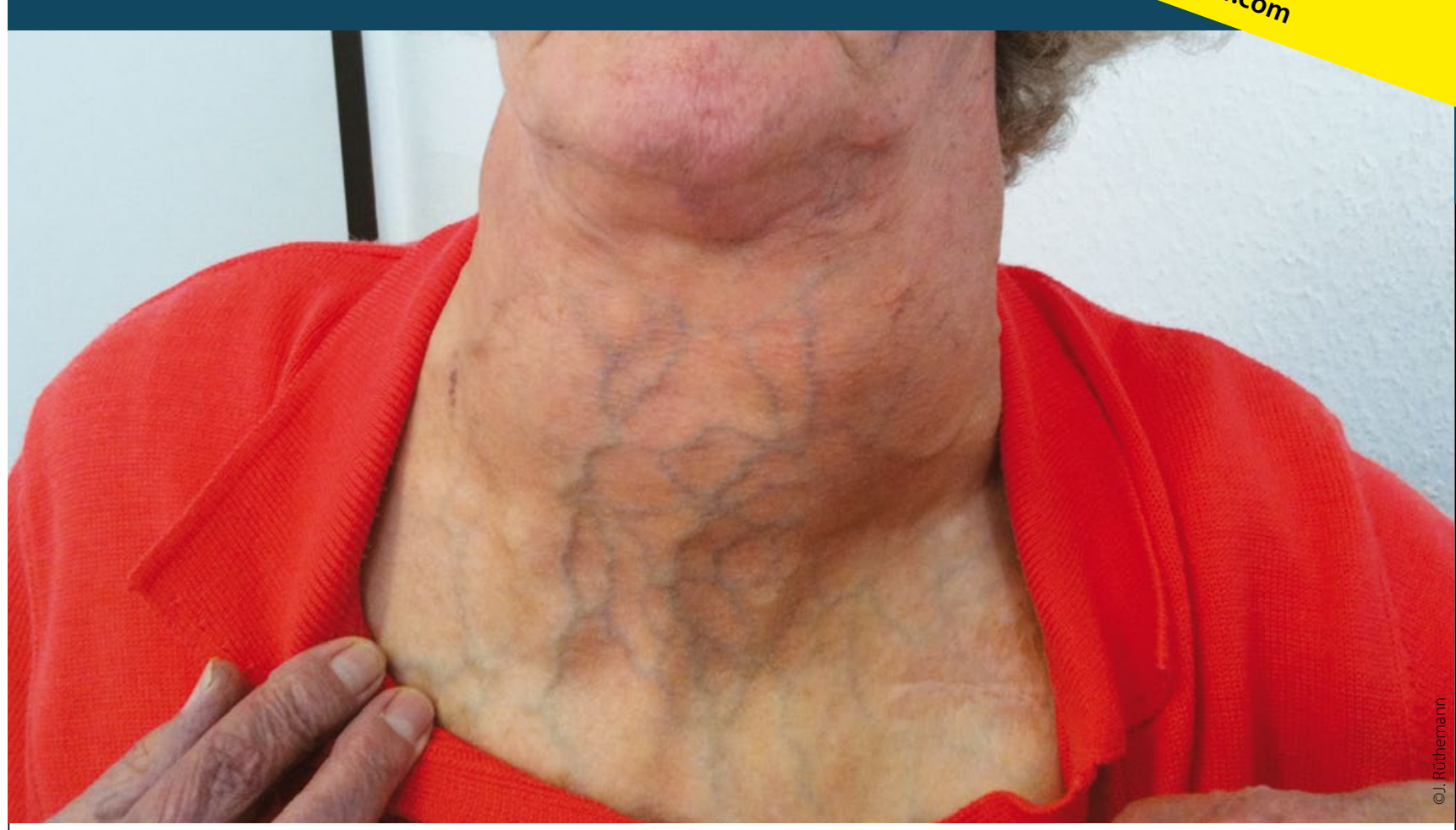

Tachykardie, Dyspnoe und Tremor

\section{Die Patientin hat einen ganz dicken Hals}

Eine 73-jährige Patientin kam mit Herzrasen, Dyspnoe, feinschlägigem Tremor der Hände und innerer Unruhe in unsere Praxis. Im EKG imponierte ein tachykardes Vorhofflimmern. Zusätzlich fiel eine massive Halsschwellung auf, die seit einigen Jahren kontinuierlich zugenommen hätte.

- Bei der weiteren Untersuchung fiel ein deutlich erniedrigtes TSH basal von $<0,01$ auf. Bei der Auskultation bestand ein inspiratorischer Stridor bei einer Sauerstoffsättigung von $98 \%$. Im Sono zeigte sich eine auf über $240 \mathrm{ml}$ angewachsene Schilddrüse mit diversen Knoten. Grundvoraussetzung für die notwendige SchilddrüsenOP war eine euthyreote Stoffwechsellage, die unter einer Carbimazol-Tagesdosis von $120 \mathrm{mg}$ erreicht wurde.

Da es der Patientin unter der thyreostatischen Therapie anfangs zunehmend besser ging, verschob sie den angesetzten OP-Termin mehrfach. Dadurch kam sie in eine massive Hypothyreose, die trotz Reduktion der Carbimazoldosis erneute internistische Probleme zur Folge hatte. Als schließlich die OP durchgeführt wurde, mussten Schilddrüsenanteile bis ins Mediastinum entfernt werden.
Sechs Monate nach der OP ist die Patientin immer noch heiser, da es intraoperativ zu einer Rekurrensparese gekommen ist.

Heiße Schilddrüsenknoten können bei entsprechender Jodexposition zu thyreotoxischen Krisen oder Hyperthyreosen führen mit Tachykardien, Tremor und Unruhe. Aufgrund der Nähe zur Luftröhre kann eine Struma zu Stridor und Dyspnoe führen. Eine Carbimazolgabe blockiert kurzzeitig die Jodaufnahme, kann aber langfristig zu einer iatrogenen Hypothyreose führen. Bei einer Schilddrüsenoperation ist aufgrund der Nähe zum Nervus recurrens, der den Kehlkopf innerviert, eine Stimmbandstörung möglich.

Keywords: goiter, thyrotoxic crisis

- Dr. med. Jens Rüthemann, MBA - Facharzt für Allgemeinmedizin, Am Kindergarten 2a, D-49843 Uelsen

\section{Weitere Infos auf \\ springermedizin.de}

Weitere Fälle unserer Leser finden Sie im Internet unter: - http://www.springermedizin.de/blickdiagnose 